\title{
Acute Renal Failure in Severe Malaria in West Africa: A Retrospective Study Conducted between 2011 and 2014 at Aristide Le Dantec Hospital in Dakar, Senegal
}

\author{
Kane $\mathrm{Y}^{1^{*}}$, Keita $\mathrm{Al}^{2}$, Lemrabott $\mathrm{AT}^{2}$, Tondi $\mathrm{ZMM}^{4}$, Faye $\mathrm{M}^{2}$, Cisse $\mathrm{MM}^{2}$, Seck $\mathrm{SM}^{3}$, Fary $\mathrm{KAEH}^{2}$, Niang $\mathrm{A}^{2}$ and Diouf $\mathrm{B}^{2}$ \\ ${ }^{1}$ Nephrology Department of Hôpital de la Paix, Faculty of health sciences, Assane Seck University, Ziguinchor, Senegal \\ ${ }^{2}$ Nephrology Department of Aristide Le Dantec Hospital, Dakar, Senegal \\ ${ }^{3}$ Nephrology Department of St Louis university hospital, Faculty of health sciences, Gaston Berger University, St-Louis, Senegal \\ ${ }^{4}$ Nephrology Department, Abdou Moumouni University, Niamey, Niger
}

"Corresponding author: Yaya Kane, Teacher and Researcher, Faculty of health sciences, Assane Seck University, Ziguinchor, Senegal, Tel: +0022177500 2165; Email: yayuskanus@yahoo.fr

Received date: November 14, 2016; Accepted date: January 20, 2017; Published date: January 27, 2017

Copyright: $\odot 2017$ Kane $Y$ et al. This is an open-access article distributed under the terms of the Creative Commons Attribution License, which permits unrestricted use, distribution, and reproduction in any medium, provided the original author and source are credited.

\begin{abstract}
Introduction: Acute renal failure (ARF) is one of the most daunting complications in severe malaria. The features of ARF in malaria are not well-known in Senegal. Our purpose when carrying out this study was to describe the epidemiological, clinical, Para clinical, treatment and outcome of those manifestations.
\end{abstract}

Patients and Methods: This was a descriptive retrospective study over a 3 year period, from 1 January 2011 to 31 December 2014. The people involved were patients with acute kidney failure during malaria. ARF in malaria was defined as urine output of less than $400 \mathrm{ml} / 24$ hour or creatinine level greater than $13 \mathrm{mg} / \mathrm{l}$ (adults), diuresis of less than $12 \mathrm{~mL} / \mathrm{kg} / 24$ hour or higher creatinine level with respect to the age (children). The data collected were analyzed using SPSS software.

Results: During the study period, we selected records of 11 patients, including 5 children and 6 adults. The average age of children was $12 \pm 2.34$ years; it was $30.83 \pm 15.34$ years for adults. The sex ratio was 1.75 . Eight patients had vomiting. Fever was observed in 10 patients. Impaired consciousness was present in 5 patients. Anuria was noted in 3 patients; 6 patients had edema syndrome. Urea average rate was $3.72 \pm 1.43 \mathrm{~g} / \mathrm{L}$, and the mean value of creatinine level was $149.96 \pm 39 \mathrm{mg} / \mathrm{L}$. There was positive thick blood in 6 out of 7 patients, and the mean parasite density was $18,106.5 \pm 14,228.5$ parasites per $\mu \mathrm{l}$. The mean hemoglobin level was $6.09 \pm 1.71 \mathrm{~g} / \mathrm{dl}$. Thrombocytopenia was present in 6 patients $(54.5 \%)$. The kidneys were well-differentiated in 4 patients. Acute tubular necrosis was diagnosed in 7 patients (63.6\%). Quinine was administered in 9 patients. Hemodialysis was performed in nine patients. The outcome was favorable in 5 patients ( 2 adults and 3 children), 2 children died.

Conclusion: This study has allowed us to notice serious cases of ARF in severe malaria, especially in children. This was diagnosed too late most of the time. Senegal must implement all human and technical resources to detect ARF in malaria as early as possible. Access to renal replacement therapy should also be facilitated.

Keywords Acute renal failure; Severe malaria; Dakar

\section{Introduction}

Malaria is a vector-borne infection caused by parasites of the genus Plasmodium transmitted by the bite the female anopheles mosquito.

It is an endemic disease in 109 countries of the world, mainly observed in tropical and subtropical regions [1,2]. It is a major public health problem, in fact almost 300 to 500 million people are infected every year with 1.5 to 2.7 million deaths per year [3].

Acute renal failure (ARF) is one of the most dreaded complications of severe malaria, with an overall incidence ranging from $0.57 \%$ to $60 \%$ and a mortality rate of up to $45 \%$ in India [4,5]. It is observed in young adults in general, and is most often secondary to infection with Plasmodium falciparum [5]. Acute tubular necrosis is the most common histological lesions [6-8].
In Senegal, studies on severe post malaria ARF (IRA-PG) included only children, and mainly focused on the prevalence $[9,10]$. With this in mind, we therefore undertook this work in order to determine the epidemiological, clinical, therapeutic and evolutionary profile of acute renal failure following severe malaria (IRA-PG) in the hospital environment.

\section{Patients and Methods}

The study was held in the Nephrology and Pediatrics department of Aristide Le Dantec University Hospital in Dakar, Senegal. This was a descriptive retrospective study of all patients who had acute renal failure during severe malaria, and who were admitted between 1 January, 2011 and 31 December, 2014. ARF was defined as urine output of less than $400 \mathrm{ml} / 24$ hours or creatinine level greater than 13 $\mathrm{mg} / \mathrm{l}$ in adults, and urine output of less than $12 \mathrm{ml} / \mathrm{kg} / 24$ hours or higher creatinine level according to age in children. Criteria for 
Citation: Kane Y, Keita Al, Lemrabott AT, Tondi ZMM, Faye M, et al. (2017) Acute Renal Failure in Severe Malaria in West Africa: A Retrospective Study Conducted between 2011 and 2014 at Aristide Le Dantec Hospital in Dakar, Senegal. J Kidney 3: 136. doi: $10.4172 / 2472-1220.1000136$

Page 2 of 4

inclusion were the occurrence of ARF with positive thick film and/or positive rapid diagnostic test to Plasmodium. The variables studied were epidemiological, clinical, Para clinical, therapeutic and evolutionary features.

The data collected were analyzed using SPSS software. The descriptive study was carried out by calculating the frequencies and proportions with their confidence intervals for categorical variables and the calculation of averages using their standard deviation for quantitative variables.

\section{Results}

During the study period, we selected 11 patient records, concerning 5 children and 6 adults. The average age of children was $12 \pm 2.34$ years with a peak incidence in the 5-10 years old. The average age of adults was $30.83 \pm 15.34$ years. The sex ratio was 1.75 .
Clinically, 3 patients ( 2 adults and 1 child) had anuria, one adult had oliguria. The edematous syndrome was present in 6 patients. Fever was observed in 10 patients. Eight patients had vomiting. Consciousness disorder was present in 5 patients.

Biologically, the average rate of urea was $3.72 \pm 1.43 \mathrm{~g} / \mathrm{L}$, and the average creatinine level was $149.96 \pm 39 \mathrm{mg} / \mathrm{L}$. The thick blood was positive in 6 out of 7 patients and the mean parasite density was $18,106.5 \pm 14,228.5$ a parasite per $\mu \mathrm{L}$. Anemia was noted in all patients and the mean hemoglobin level was $6.09 \pm 1.71 \mathrm{~g} / \mathrm{dl}$. Thrombocytopenia was present in 6 patients (54.5\%). Hyponatremia was observed in 8 patients and hyperkalemia in 5 patients. 24-hour proteinuria was $50 \mathrm{mg} / \mathrm{kg} /$ day in children shown in Tables 1 and 2 .

\begin{tabular}{|c|c|c|c|c|c|}
\hline & & \multicolumn{2}{|c|}{ Adults $(n=6)$} & \multicolumn{2}{|c|}{ Children (n=5) } \\
\hline & & Numbers & Percentage & Numbers & Percentage \\
\hline \multirow{6}{*}{ Evidence of Kidney Disorders } & Uremic syndrome & 6 & 100 & 2 & 40 \\
\hline & Edema & 2 & 33.33 & 4 & 80 \\
\hline & Oliguria & 1 & 16.67 & 0 & 0 \\
\hline & Anuria & 2 & 33.33 & 1 & 20 \\
\hline & Gross hematuria & 1 & 16.67 & 2 & 40 \\
\hline & Fever & 6 & 100 & 4 & 80 \\
\hline \multirow{8}{*}{ Extrarenal Signs } & Vomiting & 5 & 83.33 & 3 & 60 \\
\hline & Headaches & 4 & 66.67 & 0 & 0 \\
\hline & Asthenia & 6 & 100 & 5 & 100 \\
\hline & Abdominal pains & 2 & 33.33 & 1 & 20 \\
\hline & Consciousness disorder & 2 & 33.33 & 3 & 60 \\
\hline & Respiratory distress & 0 & 0 & 2 & 40 \\
\hline & Jaundice & 1 & 16.67 & 0 & 0 \\
\hline & Restlessness/Delirium & 1 & 16.67 & 0 & 0 \\
\hline
\end{tabular}

Table 1: Patients' clinical profile.

\begin{tabular}{|c|c|c|c|c|}
\hline & \multicolumn{2}{|r|}{ Adults } & \multicolumn{2}{|c|}{ Children } \\
\hline & Numbers & Percentage & Numbers & Percentage \\
\hline Hypernatremia $^{*}$ & 1 & 16.67 & 0 & 0 \\
\hline Hyponatremia* & 4 & 66.67 & 4 & 80 \\
\hline Hyperkaliemia $^{*}$ & 4 & 66.67 & 1 & 20 \\
\hline Hypokaliemia $^{*}$ & 0 & 0 & 1 & 20 \\
\hline Thrombopenia & 3 & 50 & 3 & 60 \\
\hline Hypocalcemia* $^{*}$ & 1 & 16.67 & 0 & 0 \\
\hline
\end{tabular}


Citation: Kane Y, Keita Al, Lemrabott AT, Tondi ZMM, Faye M, et al. (2017) Acute Renal Failure in Severe Malaria in West Africa: A Retrospective Study Conducted between 2011 and 2014 at Aristide Le Dantec Hospital in Dakar, Senegal. J Kidney 3: 136. doi: $10.4172 / 2472-1220.1000136$

Page 3 of 4

\begin{tabular}{|l|l|l|l|l|}
\hline Hyperphosphoremia $^{*}$ & 4 & 66.67 & 3 & 60 \\
\hline Anemia & 6 & 100 & 5 & 100 \\
\hline Alat>1.5 $\mathbf{N}^{*}$ & 1 & 33.33 & 0 & 0 \\
\hline Leucocyturia>10000* & 2 & 100 & 1 & 100 \\
\hline Hematuria>>5000 & 2 & 100 & 1 & 100 \\
\hline Proteinuria<1 g/24 hour $^{*}$ & 3 & 100 & 2 & 66.67 \\
\hline
\end{tabular}

Table 2: Patients' biological profile. ${ }^{*}$ Concentration has not been measured in all patients.

The kidneys were well-differentiated in 4 patients. Acute tubular necrosis was retained in 7 patients $(63.6 \%)$.

Quinine was used in 9 patients. Hemodialysis was performed in nine patients. The outcome was favorable in 5 patients $(2$ adults and 3 children). 2 children died.

\section{Comment}

Our study revealed that ARF in severe malaria is more common in children aged between 5 and 10 years (60\%). In a study conducted in 2012, among children in Lalya et al. found a similar result. Indeed, $48.2 \%$ of children in this study were between 5 and 10 years old [11] In Congo, Thomas et al. found in their study of children an average age of 9 years, $94.8 \%$ of them were older than 5 years. This similarity could be explained by the fact that there was kidney tropism subsequent to severe malaria in children, generally aged over 5 years, who had malaria attacks several times [12].

In our study, adults aged between 15 and 20 years and those aged over 30 years were the most affected (33\%). In India, the study carried out in adults by Mehta et al. found that most of the patients were 21 to 40 years old (75\%) [13]. This suggests that young adults may be most at risk of developing ARF in severe malaria.

Oliguria was present in one adult (16.67\%). Anuria was observed in 2 adults $(33.3 \%)$ and in one child (20\%). Oliguria or anurias are the signs usually encountered during acute tubular necrosis, main ARF lesion in severe malaria. The results of previous work are different from ours. Thomas et al. came across with oliguria in children in $85.3 \%$ of cases [12]. In Benin, 13 in 54 children had oliguria (24\%) and anuria was noted in $68.6 \%$ of cases [11]. In a study conducted in Pakistan in adults Abdul Manam et al. noted oliguria occurrence in $76.09 \%$ of cases [14]. In our study, fewer patients had impaired diuresis compared to the results of other studies. This might be because diuresis had not been collected in all patients ( 8 out of 11 patients), thus with a bias result; moreover urine collection conditions were not optimal, especially among children.

Six patients had kidney type edema syndrome including 2 adults (33.3\%) and 4 children (80\%). Lalya et al. found similar results in their study where 49 out of 54 children (90.7\%) had edematous syndrome [11]. Mehta et al. study involving 24 adults, the presence of edema in 4 of them (16.6\%) had been noted [13]. This syndrome is observed in some patients during ARF as shown in the studies mentioned above. Moreover, the etiology could be acute glomerulonephritis (AGN) which is a frequently encountered lesion in IRA-PG (acute kidney failure in severe malaria) [6]. Our study found a higher percentage of adults with edematous syndrome in comparison to Mehta et al. study, carried out in India. This difference is related to the fact that in our study, AGN was retained in 3 patients in contrast to the study of Mehta et al. where no case of AGN was reported [13].

In our study, fever was the most observed extra-renal sign (90.9\%). These results correlate those of other studies in which the frequency of fever was $96.6 \%$ [12], 93.48\% [8] or 100\% [15]. The high frequency of fever reflects the infectivity of malaria and is an element for orientation.

Loss of consciousness was observed in 5 patients including 2 adults (33.3\%) and 3 children (60\%). In Benin, in the study of Lalya et al., fewer children had impaired consciousness or 18 children out of 54 (33.3\%) [11]. This could be related to the uremic syndrome that can increase the rate of patients with consciousness disorder, since uremia has its proper neurological manifestations, such as impaired concentration, decreased cognitive function, seizures, mental clouding or coma [9].

In adults, the mean serum creatinine level was $190.66 \pm 111.41$ $\mathrm{mg} / \mathrm{L}$, it was $101.11 \pm 66.18 \mathrm{mg} / \mathrm{L}$ in children. These results are much higher than those observed in previous studies. Indeed, in the study of Lalya et al., the mean serum creatinine level of Beninese children was $56 \mathrm{mg} / \mathrm{L}$ [11]. In Pakistan, in the study by Naqvi et al. where the study population consisted of adults and children, the mean serum creatinine level was $94 \mathrm{mg} / \mathrm{L}$ [15]. This difference could be explained by the delay in consultation our people would come to the health facilities at the end-stage of kidney disease with high serum creatinine level.

Anemia was present in all patients in our study. The mean hemoglobin level was $6.09 \pm 1.71 \mathrm{~g} / \mathrm{dl}$. Two patients (one adult and one child) had severe anemia. Anemia observed in severe malaria was due to the Plasmodium falciparum that attacks the red blood cells and causes their destruction.

Thrombocytopenia was observed in 6 patients (54.5\%), 3 adults (50\%) and 3 children (60\%). A study in children in Benin noted the presence of thrombocytopenia in $20 \%$ of cases [11]. Thrombocytopenia observed in patients in these studies may be secondary to biochemical phenomena by morphological and functional changes of platelets due to the release of ADP by parasitized erythrocytes [16].

The thick film was performed in 7 patients and was positive in $85 \%$ of cases.

Plasmodium falciparum was found in all cases, which is consistent with the literature data that describe this germ as the most involved in cases of ARF in severe malaria $[4,6,17]$.

Hyperkalemia was present in 5 patients (45.4\%) including 4 adults and one child. It is a serious fluid and electrolyte disorder the cause of 
Citation: Kane Y, Keita Al, Lemrabott AT, Tondi ZMM, Faye M, et al. (2017) Acute Renal Failure in Severe Malaria in West Africa: A Retrospective Study Conducted between 2011 and 2014 at Aristide Le Dantec Hospital in Dakar, Senegal. J Kidney 3: 136. doi: $10.4172 / 2472-1220.1000136$

Page 4 of 4

which should be sought before in the advent of acute renal failure. Seriousness is linked to cardiac consequences.

Acute tubular necrosis (ATN) was diagnosed in 7 patients $(63.6 \%)$ and acute glomerulonephritis in 3 patients. The results of our series are consistent with those in the literature describing NTA as the main histological lesion of ARF during severe malaria [18]. NTA found in malaria is secondary to renal hypoperfusion. Two main mechanisms are responsible for this hypoperfusion: renal ischemia via mechanical obstruction of the capillaries by rosettes and hypovolemia $[5,17]$.

In our study, quinine was the most used treatment. In fact 9 patients (6 adults (100\%) and 3 children (60\%)) received this treatment. These results are similar to those of previous studies [11,13], which demonstrates once again the position held by quinine in the treatment of severe malaria and in connection with its fast mode of action on the Plasmodium [19].

Hemodialysis was performed in 9 patients, or $90 \%$ of the study population. In Pakistan, a study conducted in adults and children, $79.8 \%$ of patients were treated with hemodialysis [15]. In India, in the study by Mehta et al., 8 out of 22 patients (36\%) were treated with hemodialysis. The percentage of hemodialysis patients involved in studies in Pakistan and India was lower than that observed in our study, and this could be due to the difficulties in access to hemodialysis in these countries, and to the fact that some patients in these studies were treated with peritoneal dialysis [13].

The outcome was favorable in 5 patients ( 2 adults and 3 children), or $45.5 \%$ of the study population. It was negative in 6 patients with two deaths in children (40\%) caused by acute respiratory distress syndrome. In Congo in children, the outcome was good in $87.5 \%$ of cases and deaths were noted in 11 out of 87 children or $12.6 \%$. [12]. In Benin, Lalya et al. noted $7.4 \%$ of death cases [11] in their study which involved 54 children. The ARF prognosis in children in both studies was better compared to ours; this could be explained by the assumption behind the children in our study.

In Pakistan, 23.9\% cases of death [14] were reported in the study by Manam et al. The cases of death, secondary to ARF could be explained by the fact that, in these regions, the ARF during malaria is most often observed in adults [5,17].

\section{Conclusion}

ARF in severe malaria is one of the most important sign of severity. It represents one of the rarest complications, however any case of severe malaria should be investigated due to its prognosis which is generally favorable when the treatment is appropriate and applied early.

\section{References}

1. Breman JG, White NJ (1994) Harrison's Principles of Internal Medicine (Edition 13) Malaria and babesiosis. McGraw-Hill, New York, 887-896.

2. Données chiffres et stratégies clés (2005) Roll back malaria. p: 24.

3. Sachs J, Malaney P (2002) The economic and social burden of malaria. Nature 415: 680-685.

4. Mishra SK, Das BS (2008) Malaria and acute kidney injury. Semin Nephrol 28: 395-408

5. Mishra SK, Mohaprata S, Mohanty S, Patel NC, Mohapatra DN (2002) Acute Renal failure in falciparum malaria. JIACM 3: 141-147.

6. Barsoum RS (1998) Malarial nephropathies. Nephrol Dial Transplant 13: 1588-1597.

7. Eiam-ong S (2003) Malaria nephropathy. Semin Nephrol 23: 21-33.

8. Das BS (2008) Renal failure in malaria. J Vect Born Dis 45: 83-97.

9. Camara B, Gueye NR, Faye PM, Fall L, Niang D, et al. (2010) Fréquencedes signes de gravité du paludisme chez l'enfant à Dakar. Arch Pediatr 17: 1107-1108.

10. Camara B, Gueye NR, Faye PM, Fall ML, Ndiaye JL, et al. (2011) Critères de gravité et facteurs pronostiques du paludisme chez l'enfant à Dakar. Med Mal Infect 41: 63-67.

11. Lalya F, Sagbo G, Bagnan-Tossa L, Alihonou F, Tohodjede Y, et al. (2014) L'insuffisance rénale aiguë associée au paludisme chez l'enfant au CNHU Hubert K. Maga (CNHU-HK) de Cotonou, Bénin. Revue Africaine d'Anesthésiologie et de Médecine d'Urgence 19.

12. Kunuanunua TS, Aloni MN, Nsibu CN, Bodi JM, Situakibanza H, et al. (2013) Insuffisance rénale aigue dans les formes graves du paludisme chez les enfants vivant à Kinshasa. Néphrol thérap 9: 160-165.

13. Mehta KS, Halankar AR, Makwana PD, Torane PP, Satija PS, et al. (2001) Severe acute renal failure in malaria. J Postgrad Med 47: 24-26.

14. Manan AJ, Ali H, Lal M (2006) Acute renal failure associated with malaria. J Ayub Med Coll Abbottabad 18: 47-52.

15. Naqvi R, Ahmad E, Akhtar F, Naqvi A, Rizvi A (2003) Outcome in severe acute renal failure associated with malaria. Nephrol Dial Transplant 18: 1820-1823.

16. Argy N, Houze S (2014) Paludisme grave: de la physiopathologie aux nouveautés thérapeutiques. J Infect Dis 16: 13-17.

17. Barsoum RS (2000) Malarial acute renal failure. J Am Soc Nephrol 11: 2147-2154.

18. Trang TT, Phu NH, Vinh H, Hien TT, Cuong BM, et al. (1992) Acute renal failure in patients with falciparum malaria. Clin Infect Dis 15: 874-880.

19. Debord T, Imbert P, Saïssy JM, Roué R (1999) Conduite pratique du traitement antiparasitaire d'une forme grave de paludisme à Plasmodium falciparum. Med Mal Infect 29: 356-371. 